\title{
Produção e qualidade de pimentas ornamentais comestíveis cultivadas em recipientes de diferentes volumes ${ }^{(1)}$
}

\author{
CLEIDE MARIA FERREIRA PINTO(2) JANAINA MIRANDA BARBOSA(3) DANIEL ZIMMERMANN MESQUITA(3) \\ FILIPE DE OLIVEIRA ${ }^{3}$ ANA MARIA MAPELI(3) FERNANDA BASTOS SEGATTO( ${ }^{(3)}$ JOSÉ GERALDO BARBOSA $^{(3)}$
}

\section{RESUMO}

\begin{abstract}
Dentre as plantas ornamentais cultivadas em vaso, as pimentas têm se destacado pela crescente e contínua aceitação pelo mercado, devido à diversidade de cores, forma dos frutos e do porte, o que possibilita uma maior harmonia quando plantadas em vaso, o que atrai o consumidor. A caracterização dos cultivares quanto ao porte e frutificação possibilita a expansão do cultivo destas plantas em vasos, com fins ornamentais e, também, alimentícios. Desta forma, sete genótipos de pimentas com potencial ornamental (Bico, Olho de peixe, MG 302, Fafá, Roxa, Nande e Dinha) foram cultivados em vaso de diferentes volumes (300, 600, 900 e $1600 \mathrm{~mL})$, em casa de vegetação. Utilizou-se o delineamento em blocos casualizados com parcelas subdivididas, com quatro repetições. Foram avaliados o ciclo, altura e diâmetro das plantas bem como o número, comprimento, diâmetro e matérias fresca e seca dos frutos. A maior produção dos frutos foi obtida sob cultivo em recipientes de maiores volumes. Para se obter maior harmonia de vaso e efeito ornamental, a variedade Fafá deve ser cultivada em recipientes de $300 \mathrm{~mL}$, enquanto as variedades Dinha e Nande em recipientes de 600 ou $900 \mathrm{~mL}$, e as demais devem ser cultivadas em recipientes de $1600 \mathrm{~mL}$.
\end{abstract}

Palavras- chave: Capsicum annuum, Capsicum chinense, diversidade genética, plantas ornamentais, cultivo em vaso.

\section{ABSTRACT}

Production and quality of ornamental peppers grown in pots with different volumes

\begin{abstract}
The demand for ornamental peppers grown in vases is growing as they are well accepted by the market due to color diversity, shape of fruits and size of plant. Characterization of cultivars considering plant size and fructification will allow the expansion of growth for these plants in vases, with ornamental purposes as well as source of fresh fruits. Based on this, seven genotypes of peppers with ornamental potential (Bico, Olho de peixe, MG 302, Fafá, Roxa, Nande and Dinha) were grown in different volumes'vases (300, 600, 900 and 1600 $\mathrm{mL}$ ), in a greenhouse. It was used random block design with sub-parcels, with four replications. It was evaluated the plant cycle, height and diameter of plants and number, length, diameter, fresh and dry weight of fruits. The higher yield of fruits was obtained in larger vase volumes. In order to obtain better vase harmony and ornamental effect, the cultivar Fafá should be grown in 600 or $900 \mathrm{~mL}$ vases, while the remaining cultivars have to be cultivated in $1600 \mathrm{~mL}$ vases.
\end{abstract}

Keywords: Capsicum annuum, Capsicum chinense, genetic diversity, ornamental plants, cultivation in vase.

\section{INTRODUÇÃO}

O comércio de flores e plantas ornamentais no Brasil vem crescendo em média $20 \%$ ao ano e as perspectivas apontam para uma exportação em torno de 80 milhões de dólares para o ano 2007, que representa um aumento de $515 \%$ desde 2000 (BARBOZA, 2005). Ainda assim, o comércio de plantas e flores ornamentais, apresenta grande potencial a ser explorado. A exigência do mercado por produtos de qualidade e de maior valor agregado, juntamente com os efeitos da globalização, concorre para a necessidade de mudanças na forma em que as cadeias produtivas vêm operando (JUNQUEIRA \& PEETZ, 2005). Desta forma, o cultivo de espécies ornamentais comestíveis com atributos medicinais, e mesmo condimentares, em vaso, é cada vez mais comum, constituindo-se em uma agradável opção e lazer.

Várias plantas ornamentais são cultivadas em vaso e o sucesso comercial depende do apelo ao consumidor em função da beleza conferida pela qualidade, vigor, cor, forma e tamanho das folhas e dos frutos, e, sobretudo, pelo porte harmonioso da planta com o recipiente utilizado. $\mathrm{O}$ porte está estreitamente relacionado com o genótipo e pode ser harmonizado disciplinando-se o crescimento das plantas pelo tamanho de recipientes, uso de reguladores, podas, dentre outros. Assim, diferentes genótipos, mesmo os de crescimento mais expressivo podem ser cultivados em vaso, tendo o seu porte monitorado, de forma a se obter uma harmonia da planta, e, mesmo uma melhor eficiência na produção da parte aérea, particularmente de frutos.

Dentre as plantas ornamentais cultivadas em vaso, as pimentas têm se destacado pela crescente e contínua aceitação pelo mercado consumidor (UPNMOOR, 2003), em função das folhagens variegadas, diferentes portes e diversidade de forma, tamanho (alongado, arredondado, triangular, campanulado e retangular) e coloração dos frutos (vermelha, amarela, verde, laranja, salmão ou marrom), entre as espécies e mesmo em diferentes estádios de maturação na planta. Outro aspecto importante é a durabilidade dos mesmos na planta, o que

\footnotetext{
(1) Recebido para publicação em 25/08/2008 e aceito em 22/04/2010

(2) Pesquisadora da Embrapa/Epamig, Vila Gianeti, casa 46, CEP: 36570-000, Viçosa, MG

${ }^{(3)}$ Depto. de Fitotecnia/UFV, Av. P. H. Rolfs, s/n, 36570-000, Viçosa, MG.
} 
possibilita um efeito ornamental prolongado. Em princípio, qualquer espécie de pimenta poderia ser utilizada como planta ornamental, porém as de menor porte com frutos eretos e vistosos, são as mais indicadas para o plantio em vasos, devido às qualidades estéticas, principalmente na decoração de ambientes internos (VIEIRA, 2002).

De acordo com CASALI e COUTO (1984) e SOUZA e CASALI (1984), as pimentas têm como centro de origem a América, sendo cultivadas em clima tropical e semi-temperado. Além disso, são plantas de insolação plena, podendo também ser cultivadas sob menor intensidade luminosa. As pimentas malagueta, dedo de moça, cumarí do Pará, de cheiro, murupi, de bode e Bico são as mais cultivadas no Brasil, em uma área de cerca de 2000 ha, onde são produzidas 40000 toneladas, sendo MG, GO, SP, CE e RS os maiores produtores. São consumidas nas formas in natura (frescas), em molho, em conservas e desidratadas, e, de acordo com RUFINO e PENTEADO (2006), apenas no CEASA-MG, são comercializadas 230 toneladas de pimenta in natura/mês. O consumo é considerado pequeno, se comparado com as principais hortaliças (EMBRAPA, 2006) e com países como México e Espanha.

Os componentes que determinam a cor e o sabor dos frutos são os carotenóides e os_capsaicinóides, as vitaminas e os ácidos voláteis (NUEZ et al, 1996). As diversas espécies produzem frutos cujos teores de vitamina $\mathrm{C}$ superam os dos cítricos, além de serem importantes fontes de vitaminas $\mathrm{A}$, complexo B1 e B2 e de minerais como $\mathrm{Ca}, \mathrm{P}$ e Fe, além do alcalóide capsaicina, responsável pela pungência, ou seja, ardume das pimentas. De acordo com BOSLAND e VOTAVA (2000), as pimentas não ardidas do tipo "bell" (C. annuum) possuem maior quantidade de água que frutos de pimentas do tipo "New México", ardidas (C. annuum), enquanto a matéria seca, vitamina A e C estão em maiores concentrações em frutos ardidos.

A caracterização dos cultivares de pimenta quanto ao porte da planta, morfologia, tamanho, cor, forma dos frutos e pungência poderá possibilitar a expansão do cultivo, o que atenderia à demanda da indústria alimentícia, farmacêutica e ao cultivo destas plantas em vasos, com fins ornamentais e, também, alimentícios. Assim, para a inserção no mercado é importante conhecer características como relação harmônica entre tamanho e número de frutos, e particularmente, entre o porte da planta e o tamanho do recipiente.

Portanto, o presente trabalho teve como objetivos avaliar o crescimento e desenvolvimento de sete genótipos de pimenta em recipientes de diferentes volumes; determinar o tamanho do recipiente mais adequado ao genótipo, no sentido de se obter uma relação porte da planta/recipiente adequada às exigências do mercado além de disponibilizar para os produtores materiais genéticos de pimentas ornamentais comestíveis, bem como técnicas de cultivo destas espécies em recipientes com fins ornamentais e de alimentação.

\section{MATERIAL E MÉTODOS}

\subsection{Descrição das variedades e acessos}

Foram utilizadas duas variedades e cinco acessos de pimentas ornamentais provenientes do Banco de Germoplasma da EPAMIG e da UFV, com as seguintes características:

- Variedade Bico: folhas de cor verde claro, com 6 a 6,5 $\mathrm{cm}$ de comprimento e 3,2 a $3,5 \mathrm{~cm}$ de largura. Os frutos, pontiagudos, formando um bico, têm 2,5 a $3,0 \mathrm{~cm}$ de comprimento e 1,6 a 1,8 cm de largura, coloração verde-claro/ creme quando verdes e vermelha, quando maduros, aromáticos e sem ardor;

- Variedade Olho de peixe: folhas de cor verde claro, com 6 a 6,5 cm de comprimento e 3,0 a 3,5 cm de largura. Os frutos têm 1,3 a $1,5 \mathrm{~cm}$ de comprimento e 0,9 a $1 \mathrm{~cm}$ de largura, coloração verde- escuro quando verdes e amarela, quando maduros, aromáticos e com ardor;

- Acesso MG 302: folhas de cor verde bronzeado, com 2,8 a $3,2 \mathrm{~cm}$ de comprimento e 1,0 a 1,2 cm de largura. Os frutos têm 1,0 a $1,2 \mathrm{~cm}$ de comprimento e $0,6 \mathrm{~cm}$ de largura, coloração preta quando verdes e vermelha, quando maduros, aromáticos e com ardor;

- Acesso Fafá: folhas de cor verde, com 4,5 a 5,0 cm de comprimento e 1,8 a $2,2 \mathrm{~cm}$ de largura. Os frutos têm 3,0 a $3,5 \mathrm{~cm}$ de comprimento e 1,4 a 1,6 cm de largura, coloração verde quando verdes e vermelha, quando maduros, aromáticos e com ardor;

- Acesso Roxa: folhas de cor verde bronzeado, com 6 a 6,5 $\mathrm{cm}$ de comprimento e 2,2 a 2,5 cm de largura. Os frutos têm 1,5 a 1,7 cm de comprimento e 1,2 a 1,4 cm de largura, coloração preta quando verdes e vermelha, quando maduros, aromáticos e com ardor;

- Acesso Nande: folhas de cor verde, com 6 a $7 \mathrm{~cm}$ de comprimento e 2,5 a 2,7 cm de largura. Os frutos têm 4,5 a $5,0 \mathrm{~cm}$ de comprimento e 2,0 a $2,5 \mathrm{~cm}$ de largura, coloração verde quando verdes e vermelha, quando maduros, aromáticos e com ardor;

- Acesso Dinha: folhas de cor verde, com 2,8 a 3,5 cm de comprimento e 1,0 a $1,5 \mathrm{~cm}$ de largura. Os frutos têm 2,5 cm de comprimento e 0,6 a $0,7 \mathrm{~cm}$ de largura, coloração verde quando verdes e vermelha, quando maduros, aromáticos e com ardor.

\subsection{Plantio e condução das plantas}

Foi utilizado o substrato constituído da mistura solo: esterco: areia: substrato comercial $\left(\right.$ Bioplant $\left.^{\mathbb{R}}\right)$ : vermiculita, nas proporções 2:0,5:1:0,5, fertilizado com 2,5 g de superfosfato simples e $0,8 \mathrm{~g}$ de $\mathrm{KCl}$ por litro, cujas análises se encontram na (tabela 1). As mudas foram transplantadas para os respectivos vasos, quando atingiram dois a três pares de folhas. O cultivo ocorreu sob casa de vegetação e no decorrer do experimento foi efetuada a fertirrigação com $80 \mathrm{~mL} / \mathrm{vaso}$, a cada três dias, por 12 semanas, com a solução nutritiva contendo 14,$4 ; 1,95 ; 12,92 ; 2,5 ; 1,0 ; 2,44$ mmol. $L^{-1}$ de N, P, K, $\mathrm{Ca}, \mathrm{Mg}, \mathrm{S}$ e 30, 5, 50, 402 e 0,1 $\mu$ mol. $\mathrm{L}^{-1}$ de B, Cu, Fe, Mn, $\mathrm{Zn}$ e Mo, respectivamente. As irrigações foram realizadas de acordo com a necessidade.

\subsection{Parâmetros avaliados}

Quando as plantas estavam em condições adequadas ou em desenvolvimento adequado para a comercialização (frutos mais desenvolvidos com porte e cores definitivos) foram 
avaliadas as seguintes características:

- Vida pós-produção, expressa pelo número de dias entre a maturação do fruto fisiologicamente mais desenvolvido e a colheita/ senescência do último fruto maduro.

- Ciclo, expresso pelo número de dias compreendido entre o plantio e ponto de comercialização;

- Diâmetro das plantas;

- Altura das plantas;

- Número de frutos;

- Comprimento e largura dos frutos maduros;

- Largura dos frutos maduros;

- Massa total do fruto fresco (MTF), utilizando-se balança analítica, expressa em gramas.

- Massa total do fruto seco (MTS), utilizando-se balança analítica, expressa em gramas. Para determinação da MTS, os frutos foram secos em estufa a $70^{\circ} \mathrm{C}$ até peso constante.

Os dados foram interpretados usando-se análise de variância e de regressão. As médias referentes aos tratamentos qualitativos foram comparadas por meio do teste de Tukey, em nível de $5 \%$ de probabilidade. Os valores obtidos a partir de tratamentos quantitativos foram submetidos à análise de regressão, sendo o modelo escolhido com base no coeficiente de determinação, no desvio-padrão dos coeficientes de regressão e no fenômeno biológico.

\subsection{Análise estatística}

Utilizou-se o delineamento experimental em blocos casualizados com parcelas subdivididas, sendo os genótipos de pimenta dispostos nas parcelas e vasos de diferentes volumes (300, 600, 900 e $1600 \mathrm{~mL}$; altura/diâmetro: 7/10; 9/11; 12/ $14 ; 14 / 16 \mathrm{~cm}$ ) nas subparcelas, com 4 repetições, totalizando 112 unidades experimentais. Cada unidade experimental foi constituída de 1 vaso. Os dados dos parâmetros avaliados foram submetidos à ANOVA, sendo as médias dos tratamentos testadas pelo teste de Tukey a 5\% de probabilidade.

\section{RESULTADOS E DISCUSSÃO}

O acesso Fafá foi mais precoce quanto ao início da colheita, pois apresentou o primeiro fruto maduro em 16/01/2006, com antecipação de sete dias comparado aos demais genótipos, sendo que Bico comportou-se como a mais tardia, haja vista que o início da colheita ocorreu apenas em 22/02/2007. Em relação ao ciclo de produção, observou-se variação entre os genótipos, sendo que Fafá mostrou menor ciclo de colheita, com apenas 36 dias, o que foi 1,75 vezes inferior aos verificados para MG 302, Roxa, Dinha e Olho de peixe; os demais tiveram comportamento intermediário, com 50 e 56 dias para Nande e Bico, respectivamente. Estes resultados se refletem na vida pós-produção, com Fafá apresentando 53 dias de vida pósprodução, com decréscimo de $53 \%$ em relação aos demais genótipos, exceto Bico, cuja redução foi de aproximadamente 32\% (tabela 2). Segundo MEJIAS e RUANO (1990), a vida pós-produção de espécies ornamentais de $C$. annuит pode ser de 10 a 17 semanas, semelhantemente ao obtido neste trabalho, exceto para Fafá, uma vez que esta não atingiu 8 semanas.
Assim, além do efeito da planta e da frutificação, as pimentas ornamentais se destacam pela excelente vida pós-produção, já que para a maioria das espécies com fins de floração, este período é de duas a quatro semanas (LARSON, 1992) ou de apenas 20 a 30 dias, como verificado para crisântemo de vaso, dependendo do estádio de abertura das flores no ponto de comercialização (BARBOSA, 2003).

Não se observou interação entre genótipos e volume de substrato para as características altura da planta, comprimento e diâmetro dos frutos. Contudo, estes parâmetros promoveram diferenças significativas quando analisados individualmente. $\mathrm{O}$ genótipo Bico apresentou a maior altura de planta $(60,81 \mathrm{~cm})$, a qual foi cerca de 6; 3,2 e 2,6 vezes inferior ao verificado para Fafá, Nande e Dinha, que apresentaram os menores portes, respectivamente (tabela 3). Em relação ao efeito causado pelos diferentes volumes de substratos, pode-se observar que houve um aumento diretamente proporcional entre altura e volume, com diferença significativa apenas entre 300 e $1600 \mathrm{~mL}$, com incremento de 1,3 vezes (figura 1), provavelmente devido à maior disponibilidade de substrato para suprir as exigências de crescimento e desenvolvimento da planta.

$\mathrm{O}$ volume do recipiente afetou o diâmetro das plantas de todos os genótipos, observando-se um comportamento linear crescente entre os dois parâmetros, exceto para Bico, cujo modelo que melhor se ajustou foi quadrático, com ponto de máximo de $1015 \mathrm{~mL}$ (figura 2). Independente do volume utilizado, os genótipos Bico e Fafá mostraram tamanho inferior, principalmente em relação à Roxa e Olho de peixe, as quais tiveram valores mais elevados, sendo que quando cultivadas em $1600 \mathrm{~mL}$ de substrato, o decréscimo foi de 2 vezes e 3 vezes, respectivamente.

No que se refere ao comprimento e diâmetro dos frutos verificou-se uma diferença significativa entre os genótipos, com os menores valores para MG 302 e os maiores para Nande, cujo incremento foi de 5,2 e 3 vezes em relação ao comprimento e diâmetro, respectivamente, demonstrando o efeito genético (tabela 4).

$\mathrm{O}$ volume dos recipientes influenciou positivamente o número de frutos, uma vez que se observou uma relação linear crescente entre ambos, independente do genótipo considerado (figura 3). Contudo, MG 302 se destacou por demonstrar o maior valor, enquanto Fafá e Nande apresentaram os menores valores, respectivamente. Convém ressaltar que o acréscimo da primeira comparado à segunda foi de 441, 614, 483 e 586\%, para $300,600,900$ e $1600 \mathrm{~mL}$, respectivamente.

Independente do genótipo, todos mostraram uma relação linear crescente entre produção de matéria fresca dos frutos e volume de recipiente, sendo os valores obtidos para Bico e Nande os mais elevados, ocorrendo aumento de 3,9 e 2,3 em relação ao menor e maior volume, respectivamente. Os demais genótipos não apresentaram diferenças significativas (figura 4). Comportamento semelhante foi verificado para produção de matéria seca, sendo o incremento entre o volume $300 \mathrm{~mL}$ e $1600 \mathrm{~mL}$ foi de, aproximadamente, 5,$2 ; 3,0 ; 1,8 ; 2,4 ; 2,5 ; 3,1$ e 4,2 para Bico, MG 302, Fafá, Roxa, Nande, Dinha e Olho de peixe, respectivamente (figura 5).

As características dos frutos e das plantas foram influenciadas pelo volume do recipiente e genótipos, assim 
como a produção de matéria fresca e seca, havendo uma relação direta entre volume e incremento destas características. Os valores médios dos pesos frescos, do menor para o maior volume variaram de 28,7-112,6; 8,1-23,2; 19,23-35,30; 16,737,$96 ; 43,65-98,52 ; 11,24-32,79 ; 10,84-34,38 \mathrm{~g}$, para as variedades Bico, MG 302, Fafá, Roxa, Nande, Dinha e Olho de Peixe, respectivamente. Portanto, para se obter maior produção, deve-se considerar, dentre outros fatores, o volume do vaso e o genótipo.

Pimentas ornamentais em vaso são muito populares na Europa e nos Estados Unidos (BOSLAND e VOTAVA, 1999). No Brasil, o cultivo de pimentas ornamentais em vaso tem se expandido em função da fácil propagação por sementes, diversidade de cores, formas, quantidade e duração dos frutos, e, particularmente do porte anão destas plantas, tornando-as atrativas ao consumidor. Desta forma, a variedade Fafá, com altura/diâmetro médio de 10,31/14,12 cm, pode ser cultivada nos dois recipientes menores, enquanto as variedades, Dinha e Nande, cujos valores foram de 23,31/24,81 e 18,75/27,0 cm, respectivamente, devem ser cultivadas nos recipientes de $600 \mathrm{e}$ 900 mL. Já, as variedades Bico, MG 302, Roxa e Olho de peixe atingiram maior altura e diâmetro médio $(60,81 / 19,81,41,31$ / $30,56,42,18 / 35,56$ e $34,93 / 35,68 \mathrm{~cm}$ ), quando cultivadas nos maiores recipientes, ficando dentro do sugerido para plantas envasadas, ou seja, a altura das mesmas deve estar entre 1,5 a 2,5 vezes a altura do vaso, o que confere uma boa harmonia planta/vaso (BARBOSA, 2003).

\section{CONCLUSÕES}

- As maiores produções de matérias frescas e secas dos frutos foram obtidas sob cultivo em recipientes de 900 e $1600 \mathrm{~mL}$.

- Para se obter maior harmonia de vaso e efeito ornamental, a variedade Fafá deve ser cultivada em recipientes de $300 \mathrm{~mL}$, as variedades Dinha e Nande em recipientes de 600 ou 900 $\mathrm{mL}$, enquanto as demais devem ser cultivadas em recipientes de $1600 \mathrm{~mL}$.

\section{REFERÊNCIAS}

BARBOSA, J.G. Crisântemos - Produção de mudas; Cultivo para corte de flor; Cultivo em vaso e Cultivo hidropônico. Viçosa: Aprenda Fácil Editora, 2003.
BARBOZA, L.C. Jardim de oportunidades: Canteiro de negócios. Série Agronegócio, SEBRAE - Brasília, n. 1, p. 07-11, 2005.

BOSLAND, P.W.; VOTAVA, E.J. Peppers: vegetable and spice capsicums. CABI Publishing. 1999.

BOSLAND, P. W., VOTAVA, E. J. Peppers: vegetable and Spice Capsicums. CABI Publishing, 2000.

CASALI, V. W., COUTO, F.A.A. Origem e botânica de Capsicum. Informe Agropecuário, v. 10, n.113, p. 8-10, 1984.

JUNQUEIRA, A.H.; PEETZ, M.S. Las exportaciones brasileñas de flores y plantas ornamentales crecen más del 124\% entre 2001 y 2006. Horticultura Internacional, n. 56, p. 76-78, 2005.

LARSON, R. A. Introduction to Floriculture. New York: Academic Press, 1992.

NUEZ, F., ORTEGA,G., COSTA, J. El cultivo de pimientos, chiles y ajies. Mexico: Ediciones mundi-prensa, 1996.

MEJIAS, R. J.; RUANO, M.C. El cultivo industrial de plantas en macetas. S.L Réus: Ediciones de Horticultura, 1990.

RUFINO, J. L. dos SANTOS; PENTEADO, D. C. S. Importância econômica, perspectivas e potencialidades do mercado para pimentas Informe Agropecuário, v. 27, n. 235, p. 7-15, 2006.

SOUZA, R, J., CASALI, V. W. Cultivares de pimentão e pimenta. Informe Agropecuário, v. 10, n. 113, p. 14-18, 1984.

UPNMOOR, I. Cultivo de plantas ornamentais. Agropecuáris, 2003.

VIEIRA, M.A. Uso de polímero hidroabsorvente: efeitos sobre a qualidade de substratos hortícolas e crescimento de mudas de pimentão ornamental. 2002. Tese (Doutorado em Agronomia - Produção Vegetal) - Faculdade de Agronomia Eliseu Maciel, Pelotas, 2002.

Tabela 1. Valores médios para algumas características químicas do substrato utilizado no cultivo de pimentas ornamentais.

Table 1. Average values for chemical characteristics from the mix utilized in ornamental peppers.

\begin{tabular}{|c|c|c|c|c|c|c|c|c|c|c|c|c|}
\hline $\mathrm{pH}$ & $\mathrm{P}$ & $\mathrm{K}$ & $\mathrm{Ca}$ & $\mathrm{Mg}$ & $\mathrm{Al}$ & $\mathrm{H}+\mathrm{Al}$ & $\mathrm{SB}$ & $\mathrm{CTC}(\mathrm{t})$ & $\mathrm{CTC}(\mathrm{T})$ & $\mathrm{V}$ & $\mathrm{m}$ \\
\hline água & \multicolumn{2}{|c|}{$\mathrm{mg} / \mathrm{dm}^{3}$} & \multicolumn{7}{|c|}{$\mathrm{cmolc} / \mathrm{dm}^{3}$} & $\%$ \\
\hline 6,1 & 9,8 & 80 & 9,9 & 1,7 & 0,0 & 2,31 & 12,11 & 12,11 & 14,42 & 84 & 0 \\
\hline
\end{tabular}


Tabela 2. Ciclo de produção dos frutos e vida pós-produção de plantas de sete genótipos de pimentas ornamentais, cultivadas em recipientes de diferentes volumes.

Table 2. Cycle of production of fruits and post-production longevity of seven genotypes of ornamental peppers, grown on pots with different volumes.

\begin{tabular}{|c|c|c|c|c|c|}
\hline Genótipos & $\begin{array}{l}\text { Data do Ponto de } \\
\text { comercialização* }\end{array}$ & $\begin{array}{l}\text { Data da primeira } \\
\text { colheita }\end{array}$ & $\begin{array}{l}\text { Data da última } \\
\text { colheita }\end{array}$ & $\begin{array}{l}\text { Ciclo de colheita } \\
\text { (Dias) }\end{array}$ & $\begin{array}{l}\text { Vida pós-produ ção** } \\
\text { (Dias) }\end{array}$ \\
\hline Bico & $8 / 2$ & $22 / 2$ & $18 / 04$ & 56 & 70 \\
\hline MG 302 & $5 / 01$ & $23 / 01$ & $27 / 03$ & 63 & 81 \\
\hline Fafá & $29 / 12$ & $16 / 01$ & $22 / 02$ & 36 & 53 \\
\hline Roxa & $5 / 01$ & $23 / 01$ & $27 / 03$ & 63 & 81 \\
\hline Nande & $5 / 01$ & $23 / 01$ & $15 / 03$ & 50 & 81 \\
\hline Dinha & $5 / 01$ & $23 / 01$ & $27 / 03$ & 63 & 81 \\
\hline Olho de peixe & $5 / 01$ & $23 / 01$ & $27 / 03$ & 63 & 81 \\
\hline
\end{tabular}

* Primeiro fruto maduro.

** Período entre primeiro fruto maduro e última colheita.

Tabela 3. Valores médios para altura da planta de genótipos de pimentas ornamentais, cultivadas em recipientes de diferentes volumes.

Table 3. Average values for plant height of seven genotypes of the ornamental peppers, grown on pots with different volumes.

\begin{tabular}{cc}
\hline Genótipos & Altura da planta $(\mathrm{cm})$ \\
\hline Bico & $60,81 \mathrm{a}$ \\
MG 302 & $41,31 \mathrm{~b}$ \\
Fafá & $10,31 \mathrm{~d}$ \\
Roxa & $42,18 \mathrm{~b}$ \\
Nande & $18,75 \mathrm{c}$ \\
Dinha & $23,31 \mathrm{c}$ \\
Olho de peixe & $34,93 \mathrm{~b}$ \\
\hline
\end{tabular}

Médias seguidas da mesma letra maiúscula, na coluna, não diferem entre si, pelo teste de Tukey a $5 \%$. 


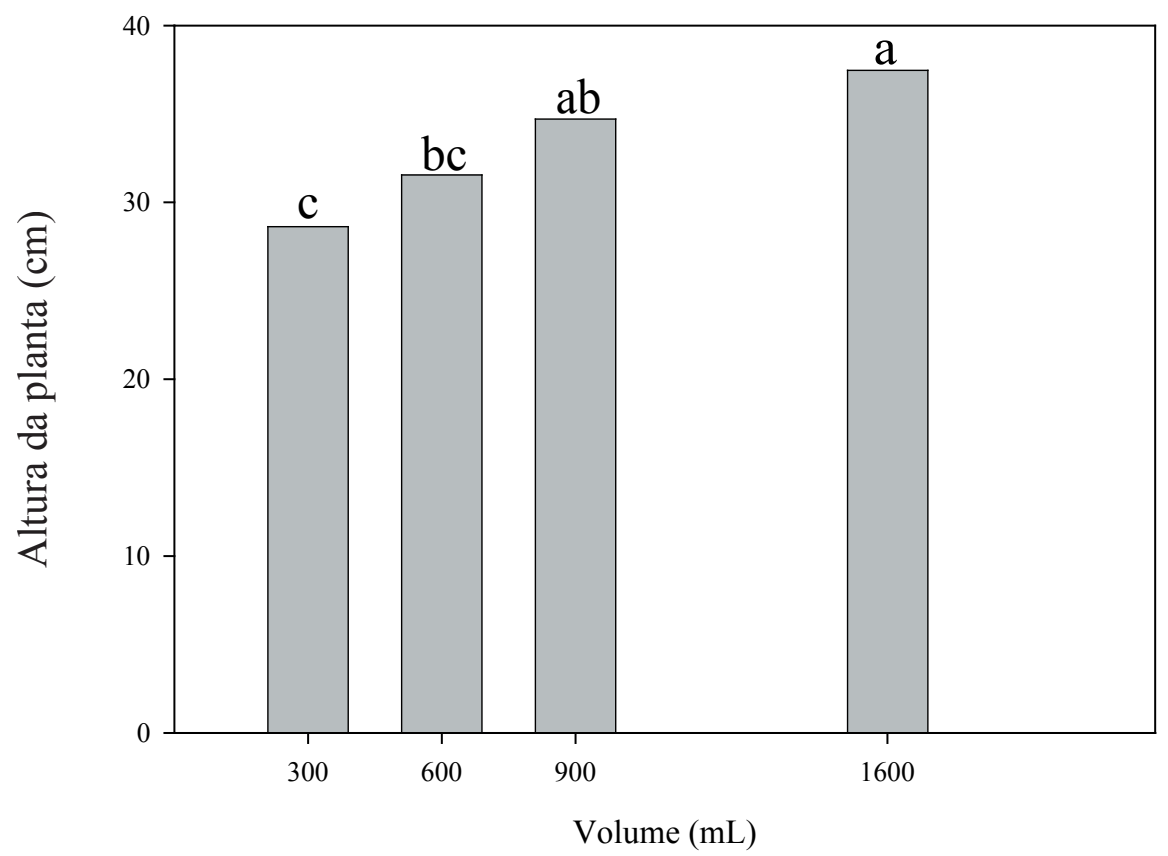

Figura 1. Altura da planta de sete genótipos de pimentas ornamentais cultivadas em recipientes de diferentes volumes. Médias seguidas da mesma letra não diferem entre si, pelo teste de Tukey a 5\%.

Figure 1. Plant height of seven genotypes of ornamental peppers, grown on pots with different volumes. Averages followed by same letter do not differ by Tukey test at $5 \%$.

Tabela 4. Comprimento médio e diâmetro do fruto de genótipos de pimentas ornamentais, cultivadas em recipientes de diferentes volumes.

Table 4. Average values for length and fruit diameter of seven genotypes of ornamental peppers, grown on pots with different volumes.

\begin{tabular}{ccc}
\hline Genótipos & Comprimento do fruto $(\mathrm{cm})$ & Diâmetro do fruto $(\mathrm{cm})$ \\
\hline Bico & $1,94 \mathrm{c}$ & $1,26 \mathrm{ab}$ \\
MG 302 & $0,74 \mathrm{e}$ & $0,53 \mathrm{e}$ \\
Fafá & $2,57 \mathrm{~b}$ & $0,70 \mathrm{c}$ \\
Roxa & $1,25 \mathrm{~d}$ & $0,80 \mathrm{c}$ \\
Nande & $3,87 \mathrm{a}$ & $1,58 \mathrm{a}$ \\
Dinha & $1,31 \mathrm{~d}$ & $0,64 \mathrm{c}$ \\
Olho de peixe & $1,09 \mathrm{de}$ & $0,89 \mathrm{bc}$
\end{tabular}

Médias seguidas da mesma letra maiúscula, na coluna, não diferem entre si, pelo teste de Tukey a $5 \%$. 

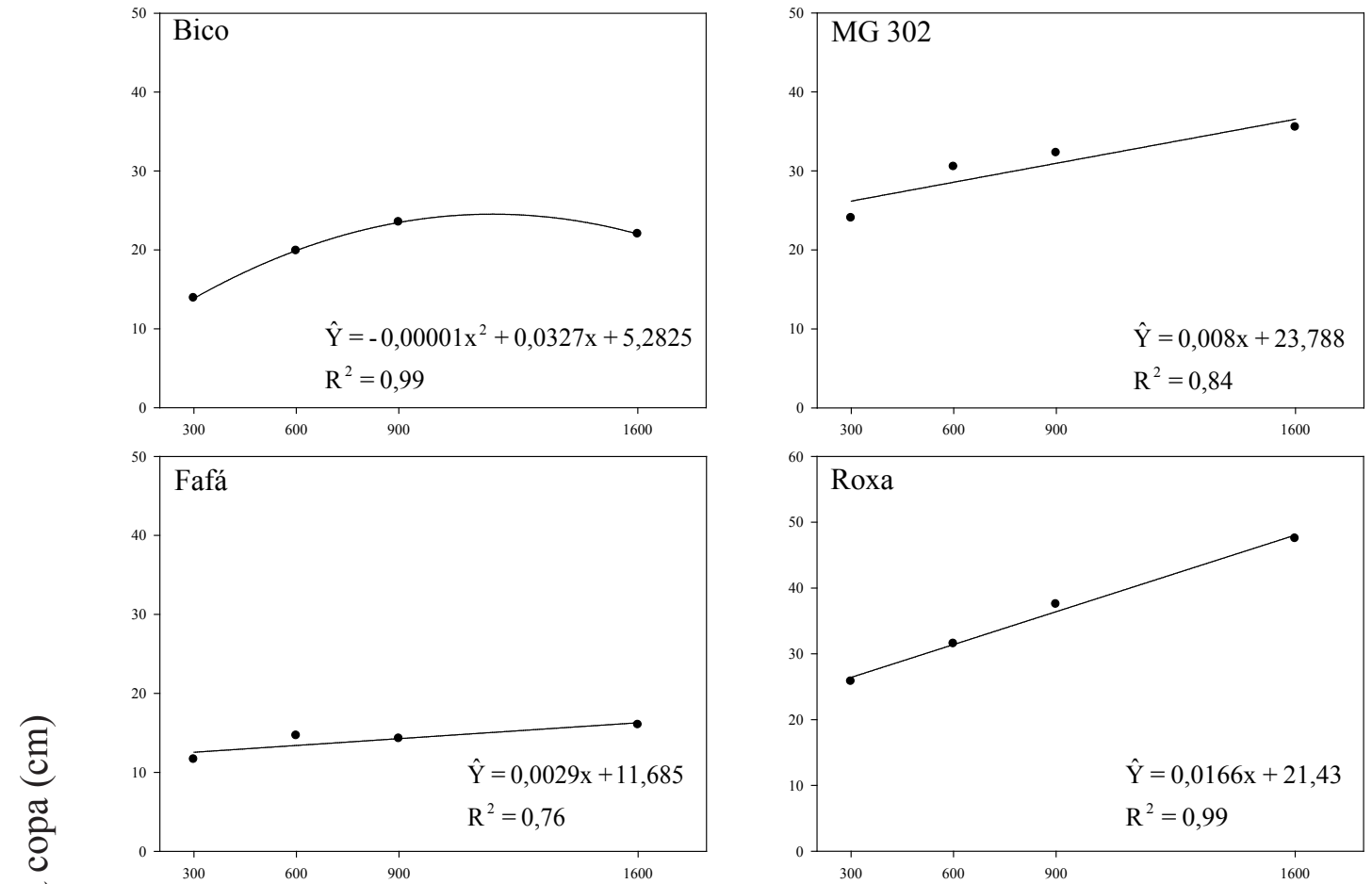

مే
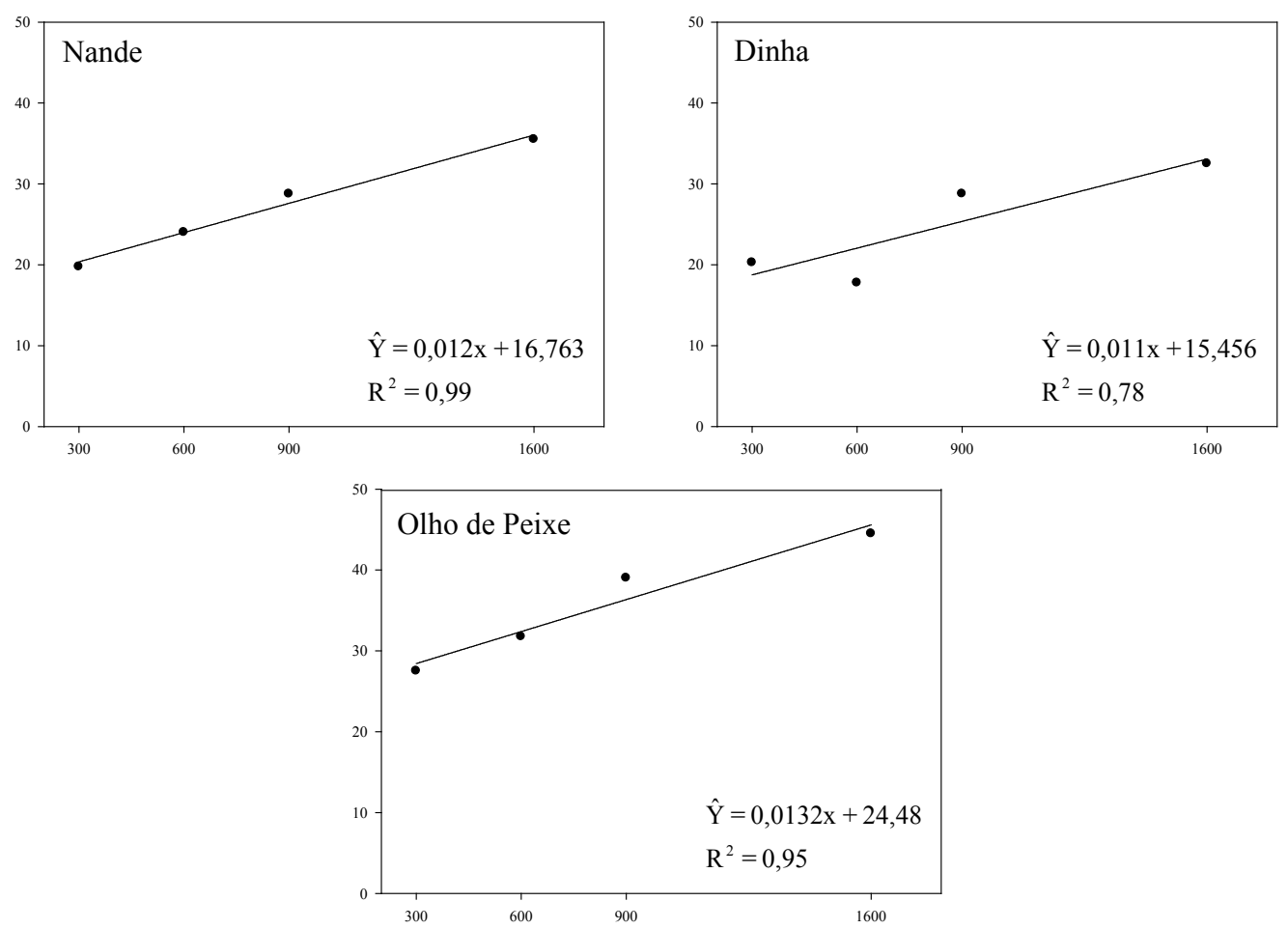

Volume (mL)

Figura 2. Diâmetro da copa de sete genótipos de pimentas ornamentais cultivadas em recipientes de diferentes volumes.

Figure 2. Diameter of canopy of seven genotypes of ornamental peppers, grown on pots with different volumes. 

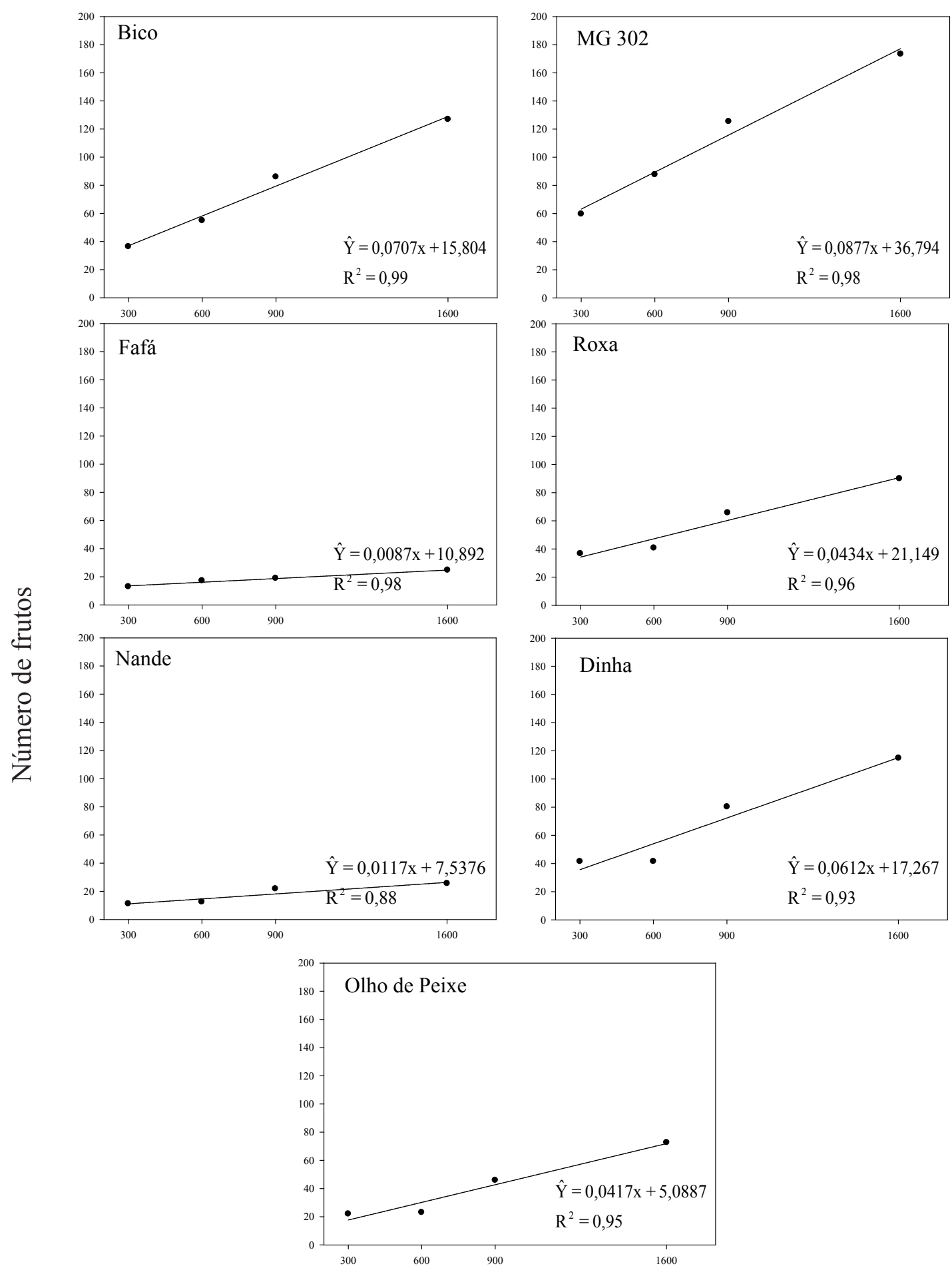

Volume $(\mathrm{mL})$

Figura 3. Número de frutos de sete genótipos de pimentas ornamentais cultivadas em recipientes de diferentes volumes. Figure 3. Number of fruits of seven genotypes of ornamental peppers, grown on pots with different volumes. 

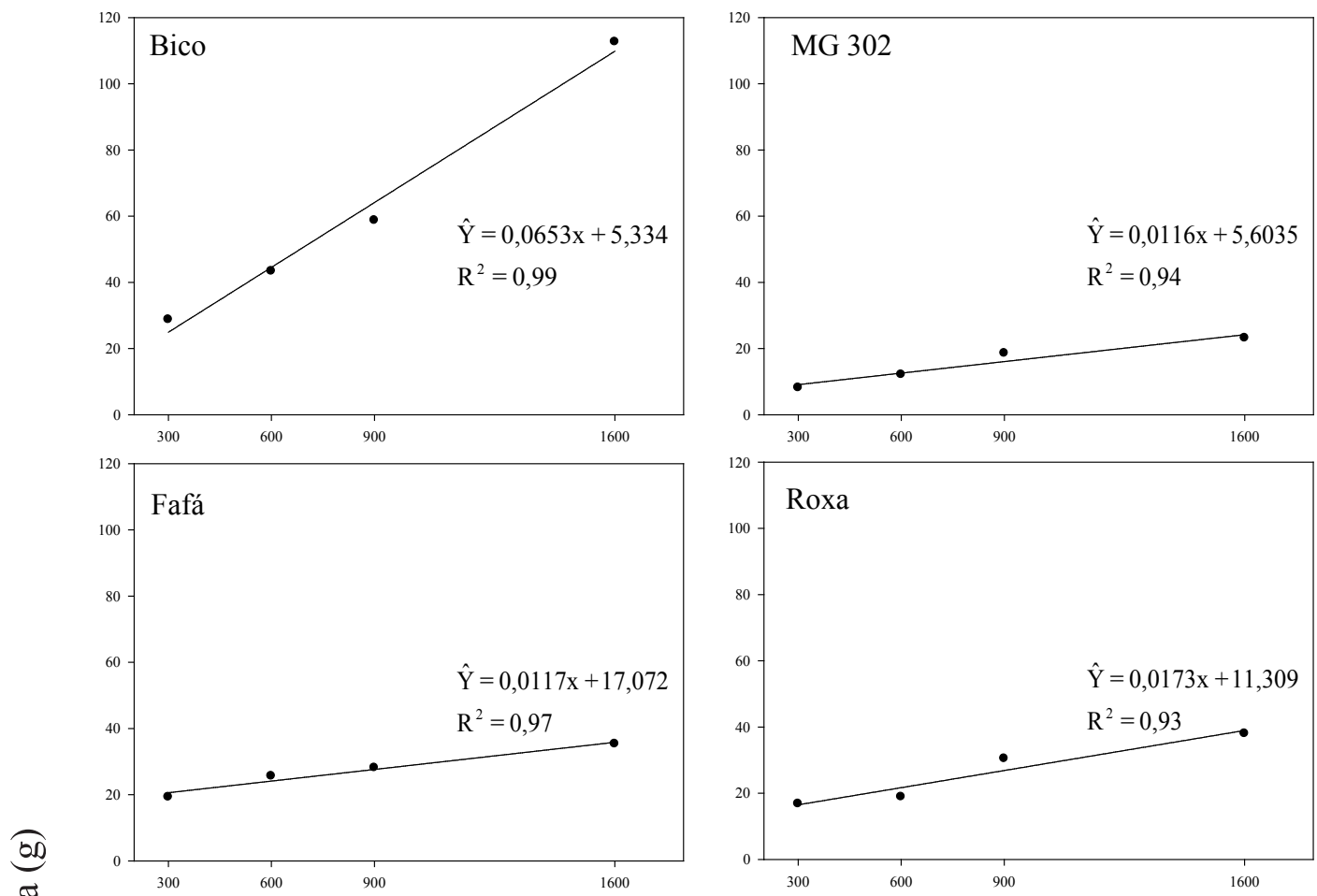

范
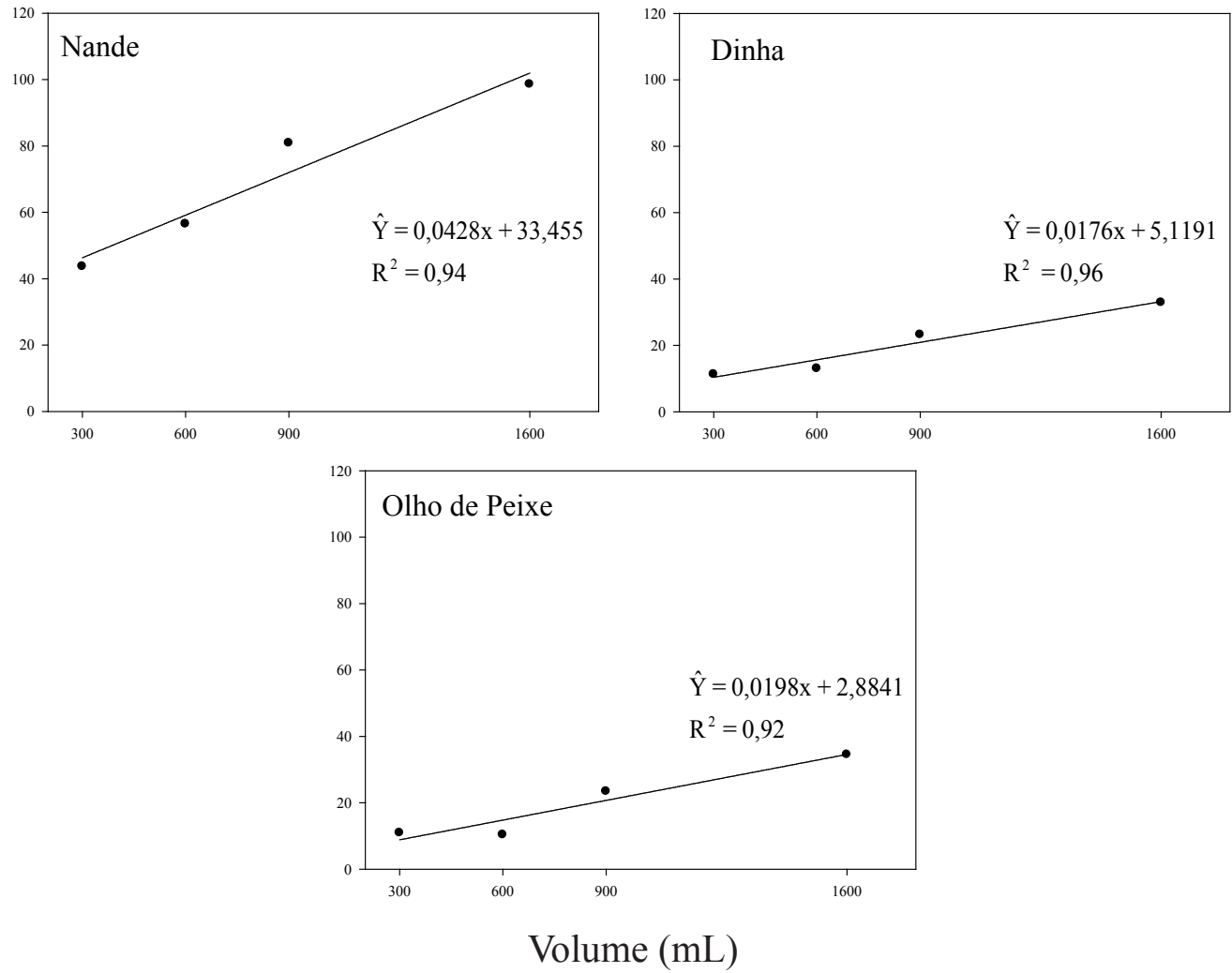

Figura 4. Matéria fresca dos frutos de sete genótipos de pimentas ornamentais cultivadas em recipientes de diferentes volumes. Figure 4. Total fresh weight of seven genotypes of ornamental peppers, grown on pots with different volumes. 

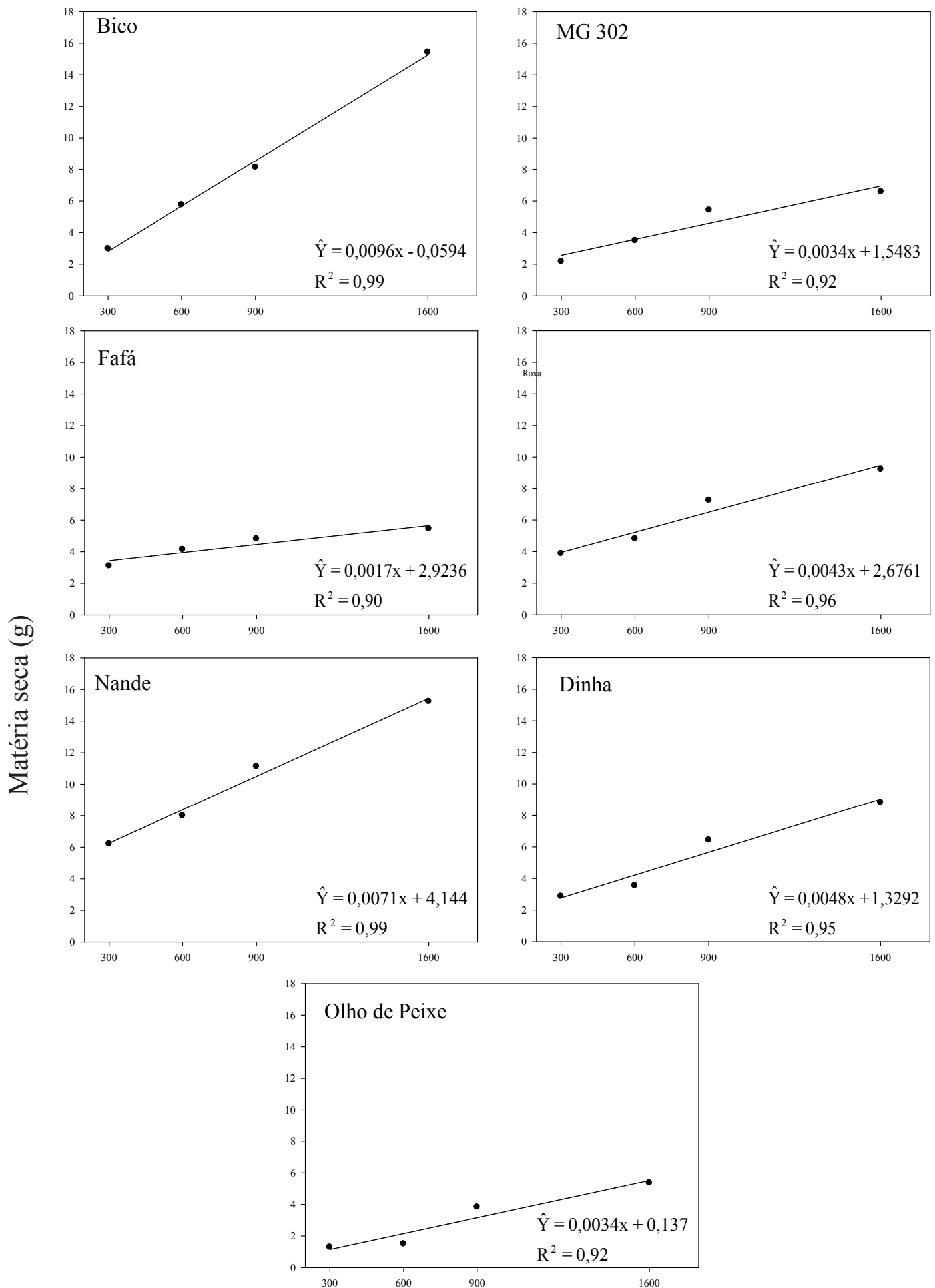

Volume $(\mathrm{mL})$

Figura 5. Matéria seca dos frutos de sete genótipos de pimentas ornamentais cultivadas em recipientes de diferentes volumes. Figure 5. Total dry weight of seven genotypes of ornamental peppers, grown on pots with different volumes. 